\title{
Pulmonary haemorrhage as a predominant cause of death in leptospirosis in Seychelles
}

\author{
Claude Yersin ${ }^{1}$, Pascal Bovet ${ }^{1,2}$, Fabrice Mérien $^{3}$, Jan Clément ${ }^{4}$, Manola Laille ${ }^{5}$, Marc Van Ranst ${ }^{4}$ and \\ Philippe Perolat ${ }^{3}{ }^{1}$ Ministry of Health, Seychelles; ${ }^{2}$ Institute of Social and Preventive Medicine, University of Lausanne, \\ Switzerland; ${ }^{3}$ Leptospira Laboratory, Institut Pasteur, Noumea, New Caledonia; ${ }^{4}$ Virology Laboratory, Department of \\ Microbiology and Immunology, University Hospitals Leuven, Belgium; 'Arboviruses Laboratory, Institut Pasteur, Noumea, \\ New Caledonia
}

\begin{abstract}
We examined the cause of death during a 12-month period (1995/96) in all consecutive patients admitted to hospital with leptospiral infection in Seychelles (Indian Ocean), where the disease is endemic. Leptospirosis was diagnosed by use of the microscopic agglutination test and a specific polymerase chain reaction assay on serum samples. Seventy-five cases were diagnosed and 6 patients died, a case fatality of $8 \%$. All 6 patients died within 9 days of onset of symptoms and within 2 days of admission for 5 of them (5 days for the $6 \mathrm{th})$. On autopsy, diffuse bilateral pulmonary haemorrhage $(\mathrm{PH})$ was found in all fatalities. Renal, cardiac, digestive and cerebral haemorrhages were also found in 5, 3,3 and 1 case(s), respectively. Incidentally, haemoptysis and lung infiltrate on chest radiographs, which suggest $\mathrm{PH}$, were found in 8 of the 69 non-fatal cases. Dengue and hantavirus infections were ruled out. In conclusion, PH appeared to be a main cause of death in leptospirosis in this population, although haemorrhage in other organs may also have contributed to fatal outcomes. This cause of death contrasts with the findings generally reported in endemic settings.
\end{abstract}

Keywords: leptospirosis, case fatality, pulmonary haemorrhage, Seychelles

\section{Introduction}

Human leptospirosis, which is caused by Leptospira pathogenic species, occurs mostly after contact, often through skin wound, with soil or water contaminated by urine of infected animals. It is an acute febrile illness with protean manifestations so that clinical diagnosis is difficult. Its severity varies from mild to rapidly fatal. Severe forms are characterized by hepatic involvement, acute renal failure (ARF), carditis, and haemorrhagic syndrome; case fatality varies from a few percent to $25 \%$ (GAUTHER et al., 1969; FAINE, 1994). Haemorrhagic presentation of leptospirosis can easily be mistaken for dengue haemorrhagic fever (DHF; dengue epidemics occurred in 1979 in Seychelles and in 1993 in the neighbouring Grand Comoro Island) or haemorrhagic fever with renal syndrome (HFRS) caused by Old World hantavirus infections (KIM et al., 1985). Definite diagnosis of leptospirosis relies essentially on biological tests. The microscopic agglutination test (MAT) currently represents the reference test of serological diagnosis, but rarely helps diagnosis during the first week of the disease when titres have not yet largely increased (FAINE, 1994). In contrast, techniques that detect leptospiral DNA by polymerase chain reaction (PCR) are more informative during the first few days of the disease (BROWN et al., 1995; MÉRIEN et al., 1995)

Leptospirosis is endemic in Seychelles. Previous reports indicated a high annual incidence ranging from 45 to 101 per 100000 , and frequent hepatic, renal, and haemorrhagic complications (PINN, 1992; YERSIN et al., 1998).

In this report we examine the cause of death in a series of consecutive acute cases identified from a prospective surveillance study conducted over 1 year, at a period during which haemodialysis was available and may have reduced mortality due to renal failure.

\section{Materials and Methods}

Study area and population

The study area covered the whole territory of Seychelles $\left(445 \mathrm{~km}^{2}\right)$, a tropical country which consists of 115 islands situated just south of the equator in the Indian Ocean. The population of 74331 concentrates on 3 islands with about $90 \%$ on the main island, Mahé.

Address for correspondence: Claude Yersin, Department of Internal Medicine, Victoria Hospital, Mont Fleuri, P.O. Box 52, Victoria, Seychelles; phone +248388000 , fax +248225416 , e-mail yersin@seychelles.net

\section{Study design}

The study was a population-based surveillance conducted between 1 April 1995 and 31 March 1996. The detailed study design was reported previously (YERSIN $e t$ al., 1998). In brief, all doctors of the country were asked to refer during this period any patient who had fever or any of the following signs or symptoms: myalgia, tender liver, jaundice, $\mathrm{ARF}$, bleeding tendency, radiological lung infiltrates, and meningism which could not be accounted for by a definite diagnusis other than leptospirosis. All patients were submitted to a questionnaire investigating demographic, socio-economic, occupational and environmental variables [methods and results are detailed elsewhere (BovET et al., 1999)]. Definite leptospirosis diagnosis was based on serology and PCR assay with blood being collected as soon as the patient was enrolled in the study (on admission for most patients) and 2-4 weeks later, except for the patients who died before collection of the second sample. All patients who died were autopsied. Patients included in the study received a course of benzylpenicillin. Informed consent was obtained from the patients or from relatives in the case of early death of the patient. The study was approved by the Ministry of Health of Seychelles.

\section{Laboratory methods}

Biochemical tests were done at Victoria Hospital laboratory and maximum values observed during the hospital stay were considered in this study. For serology and PCR assay, sera were immediately stored at $-20^{\circ}$ Celsius and submitted to diagnostic tests within 3-40 months at Institut Pasteur, Noumea, New Caledonia (leptospirosis and dengue) and at University Hospitals Leuven, Belgium (hantavirus).

MAT was performed by standard methods (FAINE, 1994) using a battery of 24 live antigens (provided by the WHO Collaborating Centre for Leptospirosis, Institut Pasteur, Paris, France) representing all major serogroups including the recently described new serogroup Hurstbridge (PEROLAT et al., 1998). The PCR assay was performed as previously described (MÉRIEN et al., 1995), with the amplification of a 331-bp fragment designed from the 16S rRNA gene of Leptospira spp. followed by a dot blot hybridization. Definite acute leptospirosis was defined if the MAT demonstrated a seroconversion, i.e., a negative first serum sample and a titre $\geqslant 1: 100$ in the second sample; or if the MAT showed $a \geqslant 4$-fold increase in antibody titre in subsequent samples; or if the PCR was positive in 1 serum sample. 
The serogroup giving the highest titre by the MAT in serial samples was considered to be the presumptive infecting serogroup (FAINE, 1994).

The sera from fatalities (except 1 because of shortage of serum) and from other patients with pulmonary haemorrhage $(\mathrm{PH})$ were examined for dengue and hantavirus infections. To detect dengue virus infection, sera were tested for total antibodies by haemagglutination inhibition assay (HIA) (CLARKE \& CASALS, 1958), for IgM antibodies by immunocapture Mac-ELISA (BUNDO \& IGARASHI, 1985), and 4 sera from fatalities (shortage of serum for 2 cases) by reverse transcriptasePCR and semi-nested PCR (LANCIOTTI et al., 1992). To detect hantavirus infection, sera were tested for IgG and IgM antibodies by recombinant nucleocapsid proteinELISA (Hantaan strain 76-118 and Puumala strain $\mathrm{Cg}$ 18-20) (IVANOV et al., 1988; ZöLLER et al., 1991). Sera were also tested by strip immuno-blot assay using an IgG-format as a variant of Western blot, using as antigen the recombinant-expressed truncated immunodominant peptide of the hantavirus nucleocapsid protein aminoterminus of SEO 80/39, resp. of PUU P360 virus, applied to a nitrocellulose membrane (courtesy of Professor B. Hjelle, University of New Mexico, USA).

\section{Definition of pulmonary haemorrhage}

$\mathrm{PH}$ was defined in fatalities on autopsy findings based on visual inspection (haemorrhagic congestion and/or consolidation) and conventional microscopy (intra-alveolar and interstitial haemorrhage). $\mathrm{PH}$ in non-fatal cases was defined as concomitant haemoptysis and radiological lung infiltrates reported by a radiologist and 2 physicians.

\section{Statistical analysis}

Student's $t$-test and $\chi^{2}$ test were used to compare continuous and categorical variables, respectively. Twotailed $P$ values below 0.05 were considered to indicate statistical significance.

\section{Case report and Results}

\section{Case report}

The history of this patient is reported in detail because of its characteristic clinical presentation and its remarkable dramatic evolution.

In August 1995, a 23-year-old man was brought dead to the emergency room of Victoria Hospital. He had never been sick until 6 days before, when fever, headache, myalgia and low back pain started. The initial symptoms were treated, after medical advice, using paracetamol (acetaminophen). On day 4, diarrhoea and abdominal pain occurred, followed the day after by cough and several episodes of haemoptysis. Relatives noticed a yellow discoloration of his eyes. On the 6 th day, he was referred in emergency to hospital and died during transportation. This young man was working as a barman and used to garden around the home. He used untreated water for drinking and for washing. Relatives reported that rats were present around his house and sometimes inside the house. Ten days before his death, he received a laceration on his hand. Autopsy revealed severe diffuse bilateral PH. Multiple haemorrhages were also seen in the heart, the kidneys and the stomach. The liver showed degenerative and necrotic changes. The MAT gave titres of $1: 1600,1: 400,1: 400$ and $1: 200$ for the serogroups Hurstbridge, Hebdomadis, Semaranga and Icterohaemorrhagiae, respectively, and the PCR assay was positive (Case 2, Table 1).

\section{Results}

Because only 1 serum was suitable for seroanalysis and PCR was negative, 5 eligible patients (none of them died) were excluded so the study included 124 out of 129 eligible patients. Leptospirosis was diagnosed in 75 patients among whom 6 died, a case-fatality rate of $8.0 \%$. Death occurred 2-9 days after the onset of symptoms and within $48 \mathrm{~h}$ of admission for 5 of them and 5 days for the 6 th

The 6 fatalities had only 1 serum available for diagnostic tests as they died before a second sample could be taken and PCR assay was positive in all of them. MAT antibody titres for serogroups not listed on Table 1 were negative. The tested sera were negative for acute dengue and hantavirus infections.

Three fatalities had high-risk occupational activities for leptospiral infection during the 15 days before the onset of symptoms ( 2 were farmers and 1 worked in forest and field), 2 had medium-risk activities (cleaning and gardening around the habitat) and 1 had low-risk activities (staying at home because of handicap). All but 1 case had foot or hand wounds during the 15 days before the onset of symptoms. Rats were present around the habitat and/or at work areas in all 6 cases, and were seen even during daytime by 5 of them.

Selected clinical, pathological and laboratory characteristics in the 6 fatalities and in the 69 non-fatal leptospirosis cases are presented in Table 2. Compared to the non-fatal cases, the 6 fatalities had significantly higher values for urea nitrogen, total bilirubin, and tended to have higher values for white blood cells, creatinine, and creatine kinase and lower values for platelets and gamma-glutamyl transferase. Chest radiograph was normal in 2 cases, showed mixed nodular lesions and confluent air-space consolidation in middle and lower fields of both lungs in 1 (Figure), and multiple, predominantly small nodular densities in the lower field of the left lung in 1. Electrocardiogram demonstrated atrial fibrillation in 1 case, ST segment depression in 1 and was normal in 2. Chest radiograph and electrocardiogram were not obtained in 2 cases

Table 1. Microscopic agglutination test (MAT) titres and polymerase chain reaction (PCR) assay results in fatal leptospirosis cases in Seychelles

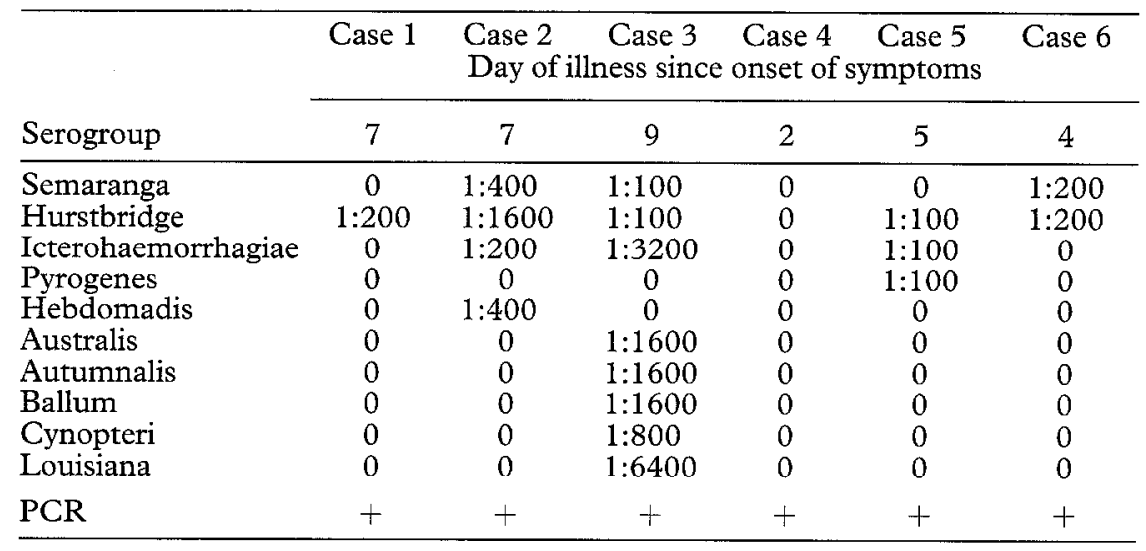


Table 2. Selected clinical, laboratory, and pathological characteristics in 6 fatal and 69 non-fatal leptospirosis cases in Seychelles

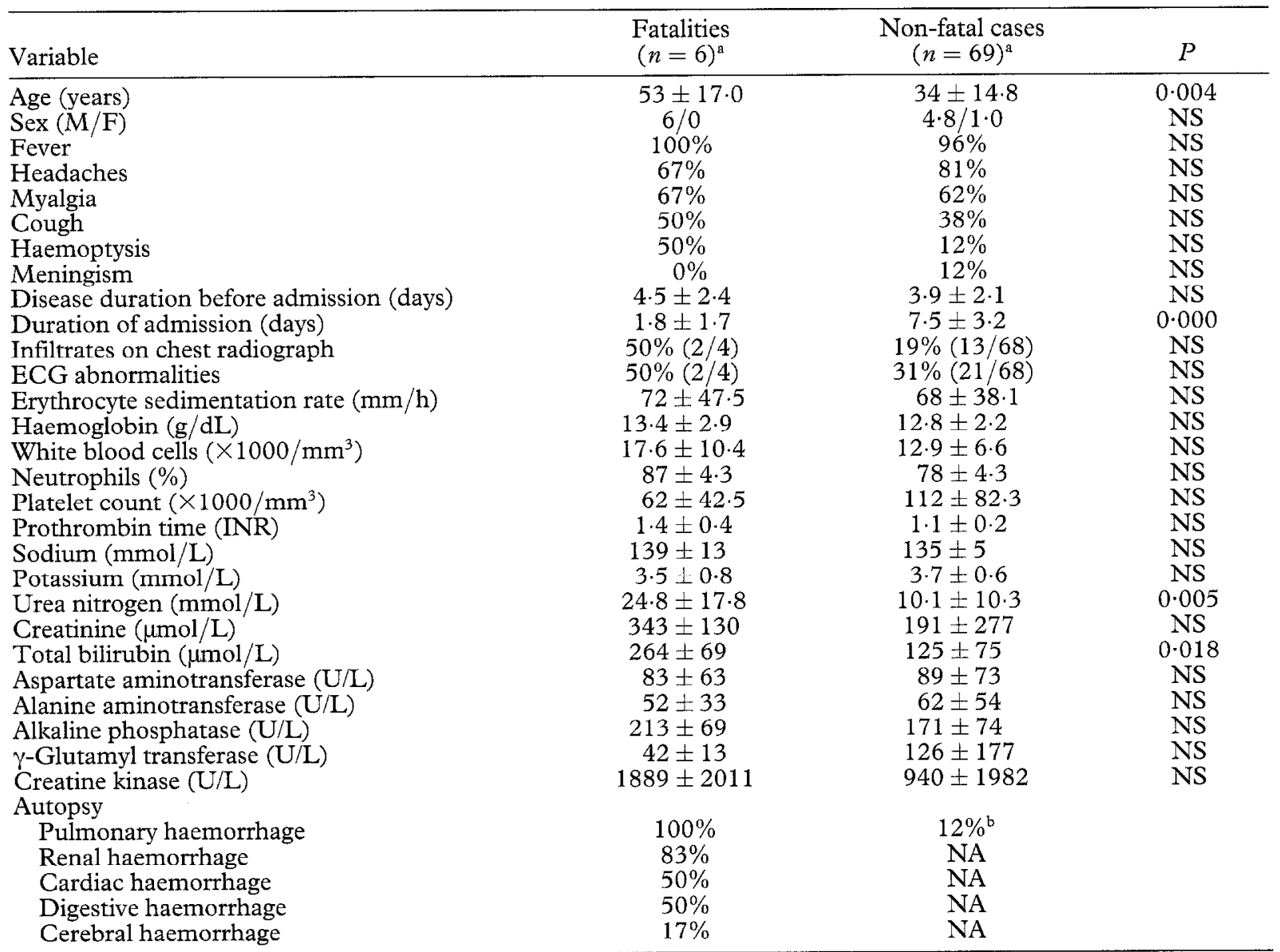

${ }^{a}$ Continuous variables are expressed as mean $\pm \mathrm{SD}$; categorical variables are expressed as proportion in percent.

${ }^{b}$ Defined as concurrent haemoptysis and pulmonary infiltrates on the chest radiograph.

NS, not significant; NA, not available.

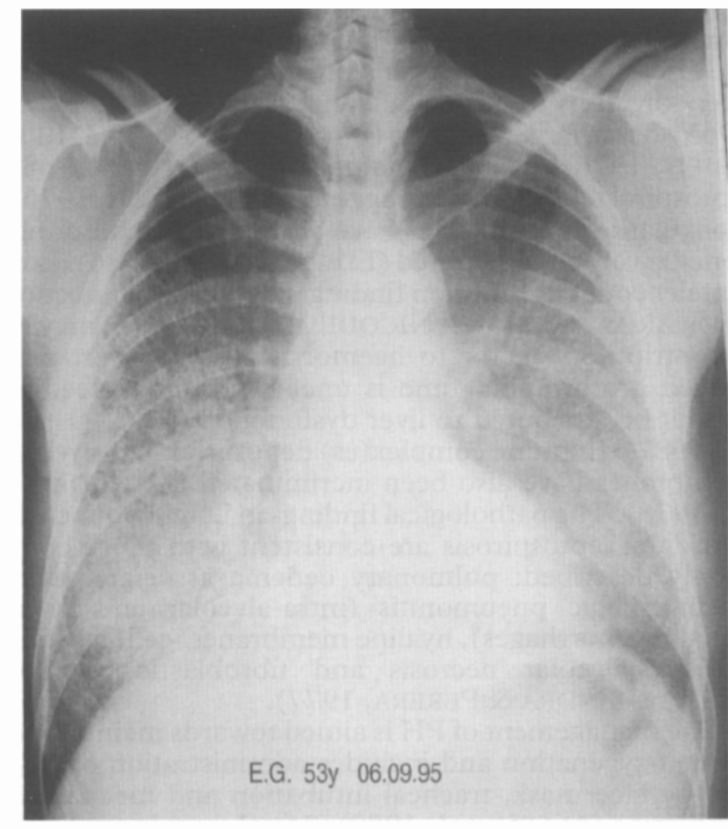

Figure. Radiograph of the chest in Case 3 showing bilateral multiple lungs infiltrates. because of early death (death occurring in these cases before admission and within $2 \mathrm{~h}$ of admission, respectively).

In the 6 fatalities autopsy showed diffuse bilateral $\mathrm{PH}$ which was considered by the pathologists to be the cause of death. In addition, Case 1 had pericardial petechiae and acute cortical necrosis of the kidneys. Case 2 presented degenerative and necrotic changes of the liver, multiple haemorrhages in the heart, the kidneys and the stomach. Degeneration of distal and proximal convoluted tubules and multiple foci of haemorrhage in both kidneys were seen in Case 3. Case 4 had cardiac interstitial vedema, oedema and petechial haemorrhages in the kidneys and the pancreas, and soft congested liver. Case 5 presented foci of haemorrhage in the myocardium, the kidneys, the liver, the adrenal glands, the cerebral ventricular walls, and the digestive mucous membrane. Case 6 had cardiac interstitial oedema, patchy ulcerative oesophagitis, bleeding ulcers in the small intestine, and oedematous kidneys with petechial haemorrhages.

Eight of the 69 non-fatal leptospirosis cases had PH defined as concurrent haemoptysis and pulmonary infiltrates on the chest radiograph (no statistical test provided, as $\mathrm{PH}$ definition differs in fatal and non-fatal cases). The presumptive infecting serogroup was Icterohaemorrhagiae in 5 and undetermined in 3 of them. All 8 sera were negative for acute dengue and hantavirus infections. 


\section{Discussion}

In the 1-year study period, 75 cases of acute leptospirosis were diagnosed (an incidence of 101/100000), among whom 6 died (a case-fatality of $8 \%$ ). Noticeably, the 6 fatalities had positive PCR assay, demonstrating the value of this diagnostic tool during the early stage of the disease when the serodiagnosis is not decisive (BROWN et al., 1995; MÉRIEN et al., 1995). Cases and fatalities occurred throughout the year, confirming the endemic nature of the disease in Seychelles. A separate analysis showed that risk factors associated with the disease in Seychelles were mostly related to the environment (BOvET et al., 1999) and typically those found in other tropical settings (F $\Lambda \mathrm{NE}, 1994$ ).

PH seemed to be the main cause of death in all 6 fatalities. All 6 fatalities had PH ascertained by autopsy, with 5 developing clinical symptoms and signs of acute respiratory failure and the 6th, who died before admission, was reported to have had haemoptysis. Respiratory distress among the 5 fatalities occurring in hospital was associated with haemoptysis in 2 , with 1 presenting a fulminant course resulting quickly in death, and the other presenting cough, breathlessness and chest pain. Respiratory distress in the 3 other fatalities occurring in hospital was characterized by restlessness, breathlessness, tachypnoea, and cyanosis. Arterial blood gas determination to quantify severity of respiratory failure was not available. Autopsy based on visual inspection and conventional microscopy (more specific investigations were not available) demonstrated haemorrhagic congestion and/or consolidation of the lungs in all 6 patients. Haemorrhages were also present in the kidneys of 5, in the myocardium and the digestive mucosa of 3 , and in the brain of 1 patient. However, even if the haemorrhagic lung involvement was visually predominant, haemorrhages in other organs (e.g., heart, brain) cannot be excluded as contributory causes of death.

$\mathrm{PH}$ developed on a rapid to fulminant mode, with 5 cases dying within $48 \mathrm{~h}$ of admission and 1 on the 5 th day of admission. In addition, the duration of symptoms before admission was short ( $1-8$ days, average of $4 \cdot 5$ days) and was not different from that for non-fatal cases. It is unlikely that any patient delayed hospital admission as there are no financial barriers (free health care in Seychelles) and transportation to the main hospital does not exceed $2 \mathrm{~h}$ from the remotest locations of the main islands. Chest radiograph done 5 and $40 \mathrm{~h}$ before death was normal in 2 of 4 cases. It has already been reported that lesions on chest radiograph do not always coincide with respiratory symptoms (PARK et al., 1989). Interestingly, platelet count and prothrombin time did not substantially differ between fatal and non-fatal cases. Other tests to investigate coagulation disorders were not available. No sign, symptom or biological test (except urea nitrogen and total bilirubin) appeared to be associated with fatal $\mathrm{PH}$, although the small number of fatalitics conveys only limitcd statistical power to identify such relationships.

As only 1 serum sample was available in the 6 fatalities, the infecting serogroup(s) could not be determined by the MAT because of common cross-agglutination between leptospiral serogroups. But Icterohaemorrhagiae was the presumptive infecting serogroup in 5 patients with non-fatal PH.

The increased occurrence of jaundice and renal failure in fatal compared to non-fatal cases can be interpreted as a reflection of the severity of the disease. $\mathrm{PH}$ concomitant with jaundice or renal failure has been reported (BOURDAIS et al., 1988; NICODEMO et al., 1997). However, TREVEJO et al. (1998) reported recently that death in epidemic leptospirosis with $\mathrm{PH}$ in Nicaragua occurred without any jaundice and without renal manifestations; no laboratory data or necropsy findings were given to assess the degree of hepatic and/or renal involvement in this patient series.

Eight non-fatal cases were likely to have some PH based on haemoptysis and pulmonary infiltrates on the chest radiograph. Our minimal criteria to define $\mathrm{PH}$ in non-fatal cases probably underestimate the number of non-fatal cases with PH as CoURTIN et al. (1998) reported that broncho-alveolar lavage may demonstrate $\mathrm{PH}$ in patients without haemoptysis or with normal chest radiograph.

Dengue and Old World hantavirus infections can mimic perfectly the classical clinical presentation of leptospirosis and their complicated forms, respectively known as DHF and HFRS, can mimic leptospirosis with PH. Aetiological viral agents of these 2 conditions are widely distributed in tropical countries but dengue and hanta viruses could be rulcd out in both the fatal and nonfatal leptospirosis cases with PH.

The cause of death in leptospirosis in Seychelles has largely changed since haemodialysis has been available in 1992. ARF and septicaemia (as a complication of peritoneal dialysis), which were frequent causes of death previously, did not cause death in our present series ( 8 of our 75 patients had to undergo haemodialysis including 1 fatal case, and 4 non-fatal cases with PH). In 1994, 2 fatal leptospirosis cases were reported and death was attributed to $\mathrm{PH}$ as ascertained by autopsy, with jaundice and $\mathrm{ARF}$ in one case and ARF alone in the other.

Classically, death in leptospirosis has been related to $\mathrm{ARF}$ and haemorrhagic syndrome (FAINE, 1994). Cardiac complications have been less frequently reported (PERTUISET et al., 1988; EVERARD et al., 1995) but cardiac involvement has not been always actively looked after. However, pulmonary manifestations in leptospirosis have been well recognized (POH \& SoH, 1970) but massive haemoptysis and acute respiratory distress syndrome have been rarcly reported (HEATH et al., 1965; TURNER \& WILLCOX, 1989) except in severe cases of leptospirosis (RAGNAUD et al., 1987; PARK et al., 1989) or during epidemic sellings in Kured (SHIM et al., 1980), Brazil (RIOS-GoNÇALVES et al., 1990) or Nicaragua (TREVEJO et al., 1998). It may be difficult to relate leptospirosis to $\mathrm{PH}$ in cases where fever and respiratory symptoms are not found together with typical signs of liver or renal impairment (TREVEJO et al., 1998; O'NEIL et al., 1991). Our findings indicate that the diagnosis of leptospirosis should be considered for all patients with fever and haemoptysis or respiratory distress syndrome in regions where leptospirosis is endemic.

Physiopathology of the pulmonary complications in leptospirosis is not well understood. Respiratory symptoms occur usually during the leptospiraemic phase of the disease. The presence of leptospires in lung tissue has been diversely reported, either rarely (HEATH et al, 1965) or in large number (PARK et al., 1989; ZAKI \& SHIEH, 1996). Capillary damage by direct action of a leptospiral toxin has been suggested ( $\mathrm{POH} \& \mathrm{SOH}, 1970)$. Coagulation disturbances have been postulated but not conclusively demonstrated (EDWARDS et al., 1986). Low platelet count, a common finding in leptospiral infection (EDWARDS et al., 1982; NICODEMO et al., 1997), may be a contributory factor to haemorrhage. However, prolonged prothrombin time is uncommon and bleeding cannot be attributed to liver dysfunction (RAGNAUD et al., 1987). Immune complex(es) deposits on the alveolar membranes have also been incriminated (DAOUDAL et $a l ., 1978$ ). The pathological findings in lungs of our cases with fatal leptospirosis are consistent with those commonly described: pulmonary oedema associated with haemorrhagic pneumonitis (intra-alveolar and interstitial haemorrhages), hyaline membranes, cellular infiltration, alveolar necrosis and fibroblastic reaction (RAMACHANDRA \& PERERA, 1977).

The management of $\mathrm{PH}$ is aimed towards maintaining tissue oxygenation and includes administration of oxygen by face mask, tracheal intubation and mechanical ventilation (ALLEN et al., 1989) (2 fatal cases in our series had been mechanically ventilated). Transfusions of platelets or fresh whole blood are likely to help control 
of the associated coagulopathy. Successful administration of steroids in severe bleeding has been anecdotally reported (KAHN, 1982) but not confirmed experimentally (YUKAWA et al., 1994). Penicillin is the antibiotic of first choice in leptospirosis (WATT et al., 1988) and resistance to this drug has not been reported so far. Further studies are needed to clarify the mechanisms resulting in pulmonary inflammation and haemorrhage and the appropriate measures to prevent and control PH in leptospirosis.

\section{Conclusion}

PH appeared to be the major contributory cause of death in leptospirosis in Seychelles. This cause of death contrasts with findings generally reported. $\mathrm{PH}$ appeared to run on a fulminant mode and death occurred within a few days of symptom onset.

\section{Acknowledgements}

The authors are indebted to Drs P. Thanikachalam, R. Krishnan and $M$. Zhangmin (Ministry of Health, Seychelles) for post-mortem examinations; Professor G. Baranton (WHO Collaborating Centre and Refcrence Laboratory on Leptospirosis, Molecular and Medical Bacteriology Unit, Pasteur Institute, Paris, France) for support of this work; I. Lecuyer, J. Pagani and D. Tribali (Leptospira Laboratory, Pasteur Institute, Noumea, New Caledonia) for expert technical assistance; and the Ministry of Health of Seychelles for its support. We are grateful to Deutsche Gesellschaft für Technische Zusammenarbeit (GTZ) Gmbh, Harare, Zimbabwe, for financial support. P.B. benefits from a grant from the Swiss National Science Foundation (No. 3233-038792.93). P.P., M.L. and F.M. were supported by the International Network of Pasteur Institutes (General Delegation, Institut Pasteur, Paris, France),

\section{References}

Allen, P., Raftery, S. \& Phelan, D. (1989). Massive pulmonary haemorrhage due to leptospirosis. Intensive Care Medicine, 15, 322-324.

Bourdais, A., Lonjon, B., Vergez-Pascal, R., Fournier, A. \& AhLo, W. (1988). Respiratory complications of leptospirosis. Apropos of 6 cases, 3 of which show hemodynamic studies. Médecine Tropicale, 48, 149-160.

Bovet, P., Yersin, C., Mérien, F., Davis, C. E. \& Perolat, P. (1999). Leptospirosis frequency and associated factors in a tropical country: a population-based case-control study in the Seychelles islands (Indian Ocean). International foumal of Epidemiology, 28, 583-590.

Brown, P. D., Gravekamp, C., Carrington, D. G., van de Kemp, H., Hartskeerl, R. A., Edwards, C. N., Everard, C. O. R., Terpstra, W. J. \& Levett, P. N. (1995). Evaluation of the polymerase chain reaction for early diagnosis of leptospirosis. Foumal of Medical Microbiology, 43, 110-114.

Bundo, K. \& Igarashi, A. (1985). Antibody-capture ELISA for detcction of immunoglobulin $M$ antibodies in scra from Japanese encephalitis and dengue hemorrhagic fever patients. foumal of Virological Methods, 11, 15-22.

Clarke, D. H. \& Casals, J. (1958). Techniques for haemagglutination and haemagglutination inhibition with arthropodborne virus. American Journal of Tropical Medicine and Hygiene, 7, 561-573.

Courtin, J.-P., Di Francia, M., Du Couedic, L., Poubeau, P., Mahé, C., Bapteste, J. \& Arvin-Berod, C. (1998). Les manifestations respiratoires de la leptospirose. Etude rétrospective de 91 cas (1978-1994). Revue de Pneumologie Clinique, 54, 382-392.

Daoudal, P., Mathieu, P., Bloch, B. \& Barale, F. (1978). Leplospirose. Immunisation antimembrane basale glomerulaire. Nouvelle Presse Médicale, 7, 3535-3537.

Edwards, C. N., Nicholson, G. D. \& Everard, C. O. (1982). Thrombocytopenia in leptospirosis. American foumal of Tropical Medicine and Hygiene, 31, 827-829.

Edwards, C. N., Nicholson, G. D. Hassel, T. A., Everard, C. O. R. \& Callender, J. (1986). Thrombocytopenia in leptospirosis: the absence of evidence for disseminated intravascular coagulation. American foumal of Tropical Medicine and Hygiene, 35, 352-354.

Everard, C. O.R., Edwards, C. N., Everard, J. D. \& Carrington, D. G. (1995). A twelve-year study of leptospirosis on Barbados. European fournal of Epidemiology, 11, 311-320.

Faine, S. (1994). Leptospira and Leptospirosis. Boca Raton: CRC Press.

Gauthier, R., Brochier, A., Lavallée, M., Comby, F. \& Lataste-
Dorolle, C. (1969). New contributions to the study of leptospirosis in Reunion. I. Study of 70 cases, 18 of which fatal: clinical and biological aspects. Physiopathological considerations. Bulletin de la Société de Pathologie Exotique, 62, 493-508.

Healh, C. W., Alexander, A. D. \& Galton, M. M. (1965). Leptospirosis in the United States. Analysis of 483 cases in man, 1949-1961. New England Fournal of Medicine, 273, $857-861,915-922$

Ivanov, A. P., Tkachenko, E. A., Petrov, V. A., Pashkov, A. J., Dzagurova, T. K., Vladimirova, T. P., Voronkova, G. M. \& van der Groen, G. (1988). Enzyme immunoassay for the detection of virus specific IgG and IgM antibody in patients with HFRS. Archives of Virology, 100, 1-7.

Kahn, J. B. (1982). A case of Weil's disease requiring steroid therapy for thrombocytopenia and bleeding. American fournal of Tropical Medicine and Hygiene, 31, 1213-1215.

Kim, J. S., Lee, J. W., Oh, D. K., In, S. D., Lee, Y. H. \& Cho, W. H. (1985). An epidemiological study on identification of cause for epidemic pulmonary hemorrhagic fever. Foumal of the Korean Medical Association, 28, 77-78.

Lanciotti, R. S., Calisher, C. H., Gubler, D. J., Chang, G. J. \& Vorndam, A. V. (1992). Rapid detection and typing of dengue viruses from clinical samples by using reverse transcriptasepolymerase chain reaction. Foumal of Clinical Microbiology, 30, 545-551.

Mérien, F., Baranton, G. \& Perolat, P. (1995), Comparison of polymerase chain reaction with microagglutination test and culture for diagnosis of leptospirosis. Foumal of Infectious Diseases, 172, 281-285.

Nicodemo, A. C., Duarte, M. I. S., Alves, V. A. F., Takakura, C. F. H., Santos, R. T. M. \& Nicodemo, E. L. (199'). Lung lesions in human leptospirosis: microscopic, immunohistochemical, and ultrastructural features related to thrombocytopenia. American Journal of Tropical Medicine and Hygiene, 56, $181-187$.

O'Neil, K. M., Rickman, L. S. \& Lazarus, A. A. (1991). Pulmonary manifestations of leptospirosis. Review of Infectious Diseases, 13, 705-709.

Park, S. K., Lee, S. H., Rhee, Y. K., Kang, S. K., Kim, K. J., Kim, M. C., Kim, K. W. \& Chang, W. H. (1989). Leptospirosis in Chonbuk province of Korea in 1987: a study of 93 patients. American foumal of Tropical Medicine and Hygiene, 41, 345-351.

Perolat, P., Chappel, R. J., Adler, B., Baranton, G., Bulach, D. M., Billinghurst, M. L., Letocart, M., Merien, F. \& Serrano, M. S. (1998). Leptospira fainei sp. nov. isolated from pigs in Australia. International foumal of Systematic Bacteriology, 48 , 851-858.

Pertuiset, E., Fen Chong, M., Duval, G. \& Génin, R. (1988). $\Lambda$ spects cliniques et facteurs pronostiques des leptospiroses ictéro-hémorragiques de l'adulte. Revue de Médecine Interne, 9, 487-493.

Pinn, G. (1992) . Teptospirosis in the Seychelles. Medicnt Fournal of Australia, 156, 163-167.

Poh, S. C. \& Soh, C. S. (1970). Lung manifestations in leptospirosis. Thorax, 25, 751-755.

Ragnaud, J. M., Dupon, M., Echinard, E., Teboulle, D. \& Wone, C. (1987). Manifestations pulmonaires au cours de leptospiroses ictero-hémorragiques sévères. Annales de Médecine Interne, 138, 282-286.

Ramachandra, S. \& Perera, M. V. (1977), Cardiac and pulmonary involvement in leptospirosis. Transactions of the Royal Suciely of Tropical Medicine and Hyyiente, 71, 56-59.

Rios-Gonçalves, A. J., Capone, G., Paz, N. A., Paulo, R. V. V., Dias, T. B. C. M., Lago, V. C. C. \& Carvalho, L. M. A. (1990). Leptospirose. Observaçes sobre as mudanças dos padres clínicos no Rio de Janeiro após a grande epidemia de 1988. Arquivos Brasilieros de Medicina, 64, 389-397.

Shim, Y. H., Shim, B. S., Choe, K. H., Kim, D. S., Shin, K. C., Lee, K. L., Lee, Y. W., Kim, Y., Chin, C. J., Lee, J. T. \& Chai, I. S. (1980). Epidemic pulmonary hemorrhagic fever. I. Epidemiological and clinical observations. Foumal of the Korean Medical Association, 23, 131-144.

Trevejo, R. I., Rigau-Pérez, J. G., Ashford, D. A., McClure, E. M., Jarquin-Gonzalez, C., Amador, J. J., de Ios Reyes, J. O., Gonzales, A., Zaki, S. R., Shieh, W.-I., McLean, R. G., Nasci, R. S., Weyant, R. S., Bolin, C. A., Bragg, S. L., Perkins, B. A. \& Spiegel, R. A. (1998). Epidemic leptospirosis associated with pulmonary hemorrhagc-Nicaragua, 1995. Foumal of Infectious Diseases, 178, 1457-1463.

Turner, J. S. \& Willcox, P. A. (1989). Respiratory failure in leptospirosis. Quarterly foumal of Medicine, 72, 841-847.

Watt, G., Padre, L. P., Tuazon, M. L., Calubaquib, C., Santiago, E., Ranon, C. P. \& Laughlin, L. W. (1988). 
Placebo-controlled trial of intravenous penicillin for severe and late leptospirosis. Lancet, $\mathbf{i}, 433-435$.

Yersin, C., Bovet, P., Mérien, F., Wong, T., Panowsky, J. \&

Perolat, P. (1998). Human leptospirosis in the Seychelles

(Indian Ocean): a population-based study. American foumal of Tropical Medicine and Hygiene, 59, $933 \% 940$.

Yukawa, M., Kamata, H., Ohba, S., Kadoi, K. \& Mochizuki, K.

(1994). Effect of immune scrum, an antibiotic, and

corticosteroid used alone or in combination on experimental leptospirosis in Mongolian gerbils (Meriones unguiculatus).

fournal of Basic Microbiology, 34, 49-55.

Zaki, S. R. \& Shieh, W. J. (1996). Epidemic Working Group at
Ministry of Health in Nicaragua, Pan American Health Organization, US Department of Agriculture, Centers for Disease Control and Prevention. Leptospirosis associated with outbreak of acute febrile illness and pulmonary haemorrhage, Nicaragua, 1995 [letter]. Lancet, 347, 535.

Zöller, L., Yang, S. \& Zeyer, M. (1991). Rapid diagnosis of hemorrhagic fever with renal syndrome due to Hantavirus. Lancet, 338, 183.

Received 3 Fune 1999; revised 16 September 1999; accepted for publication 21 September 1999

\title{
Announcements
}

\section{American Society of Tropical Medicine and Hygiene 49th Annual Meeting}

Houston, TX, USA

29 October-2 November 2000

For more information, please contact ASTMH Headquarters, 60 Revere Drive, Suite 500, Northbrook, IL 60062, USA; phone +1 847480 9592, fax +1 8474809282 , e-mail astmh@astmh.org, web site www.astmh.org

\section{3rd MOH-AMM Scientific Meeting and \\ International Congress of Medicine in the Tropics}

\author{
Kuala Lumpur, Malaysia \\ 1-4 November 2000
}

This meeting is organized by the Ministry of Health/Academy of Medicine of Malaysia.

For further information please contact the Congress Secretariat, 3rd MOH-AMM Scientific Meeting, Academy of Medicine of Malaysia, 19 Jalan Folly Barat, 50480 Kuala Lumpur, Malaysia; phone +6032530100 or 2530200 , fax +6032530900 , e-mail acadmed@po.jaring.my

\section{Utilising the Genome Sequence of Parasitic Protozoa Advance Notice of a Royal Society Discussion Meeting}

\section{1-22 March 2001}

Organized by K. Vickerman, FRS, J. Blackwell, C. Newbold and C. M. R. Turner

For further information contact Mike Turner, Institute of Biomedical and Life Sciences, Division of Infection and Immunity, Joscph Black Building, University of Glasgow, Glasgow G12 8QQ, UK; e-mail m.turner@bio.gla.ac.uk 